\title{
EVALUASI IMPLEMENTASI PELAYANAN \\ INFORMASI OBAT PASIEN RAWAT JALAN DI \\ INSTALASI FARMASI RUMAH SAKIT \\ YOGYAKARTA
}

\section{EVALUATION OF THE DRUG INFORMATION SERVICE IMPLEMENTATION OF OUTPATIENT IN PHARMACY INSTALLATION OF YOGYAKARTA HOSPITAL}

\author{
Faridah Baroroh \\ Fakultas Farmasi Universitas Ahmad Dahlan \\ Jl. Prof. Dr. Soepomo, SH, Telp. (0274) 379418 \\ farida_b0702@yahoo.co.id
}

\section{Abstrak}

Upaya untuk menunjang pelayanan kesehatan yang bermutu tinggi di rumah sakit, Instalasi Farmasi Rumah Sakit Yogyakarta perlu melakukan evaluasi implementasi pelayanan informasi obat pasien rawat jalan. Tujuan dari penelitian ini adalah untuk mengetahui realisasi implementasi pelayanan informasi obat pasien rawat jalan di instalasi farmasi Rumah Sakit Yogyakarta jika dibandingkan dengan target yang diinginkan. Penelitian ini merupakan penelitian deskriptif dengan melihat dokumentasi data sekunder tentang program kerja instalasi farmasi, wawancara dengan apoteker yang bertugas melayani pasien rawatjalan sebagai subyek penelitian, serta pengamatan langsung terhadap pelayanan informasi obat pasien rawat jalan. Untuk mengetahui perbandingan realisasi dengan target yang diinginkan digunakan analisis kesenjangan. Hasil penelitian evaluasi implementasi pelayanan informasi obat pasien rawat jalan terlaksana dengan realisasi terjadi kesenjangan negatif sebesar (-0,67\%). Komponen informasi obat yang disampaikan meliputi khasiat, cara penggunaan, aturan pakai, lama penggunaan obat, efek samping obat, sedangkan komponen informasi obat yang tidak disampaikan di instalasi farmasi Rumah Sakit Yogyakarta yaitu informasi jadwal pengobatan, dan tanda-tanda toksisitas.

Kata Kunci :Rumah Sakit Yogyakarta, Implementasi, Pelayanan Informasi Obat 


\section{Abstract}

To support high quality health service in hospital, Pharmacy Installation of Yogyakarta Hospital needs to evaluate implementation of drug information service for outpatient. This study is aimed to identify the realization of drug information service of outpatient implementation of Pharmacy Installation of Yogyakarta Hospital compared to the specified target. This study was carried out by descriptive design using secondary data of Pharmacy Installation programs, interview with a pharmacist was assigned outpatients serving as research subjects, as well as direct observation of drug information service for outpatient. Gap analysis was used to identify the comparison between the realization and specified target. The result of this study of evaluation in drug information service implementation of outpatient showed negative gaps as much as $-0.67 \%$. The component information presented included the efficacy of drugs, how to use, the rules of use, duration of drug use, drug side effects, however the components of drug information that is unallowed in Pharmacy Installation of Yogyakarta Hospital how shcedule of drug use and signs toxicity.

Keywords : Yogyakarta Hospital, Implementation, Drug Information Service

\section{PENDAHULUAN}

Evaluasi implementasi strategi yaitu sebuah proses yang memonitor aktivitas dan hasil kinerja perusahaan supaya kinerjanya aktual dan dapat dibandingkan dengan kinerja yang diinginkan (Hunger dan Wheelen, 2006).

Berdasarkan Surat Keputusan Menteri Kesehatan Nomor 1197/Menkes/SK/X/2004 tentang Standar Pelayanan Farmasi Rumah Sakit menyebutkan bahwa pelayanan farmasi rumah sakit adalah bagian yang tidak terpisahkan dari sistem pelayanan kesehatan rumah sakit yang berorientasi kepada pelayanan pasien, penyediaan obat yang bermutu, termasuk pelayanan farmasi klinik yang terjangkau bagi semua lapisan masyarakat. Praktek pelayanan kefarmasian merupakan kegiatan yang terpadu dengan tujuan mengidentifikasi, men- cegah dan me- nyelesaikan masalah yang berhubungan dengan kesehatan (Anonim, 2004).

Pelayanan informasi obat merupakan suatu kegiatan untuk memberikan pelayanan informasi obat yang akurat dan objektif dalam hubungannya dengan perawatan pasien, pelayanan informasi obat sangat penting dalam upaya menunjang budaya pengelolaan dan penggunaan obat secara rasional (Julianti dan Widayanti, 1996). Pelayanan informasi obat sangat diperlukan, terlebih lagi banyak pasien yang belum mendapatkan informasi obat secara memadai tentang obat yang digunakan, karena penggunaan obat yang tidak benar bisa membahayakan.

Rumah Sakit Yogyakarta atau Rumah Sakit Umum Daerah Kota Yogyakarta adalah rumah sakit milik 
Pemerintah Daerah Kota Yogyakarta. Rumah Sakit Yogyakarta ditetapkan menjadi rumah sakit kelas $\mathrm{B}$ sesuai dengan keputusan Mentri Kesehatan RI No1224/MENKES/SK/XI/2007 pada tanggal 27 November 2007. Rumah Sakit Yogyakarta menyelenggarakan kegiatan pelayanan spesialistik dasar dan spealistik lainnya meliputi penyakit dalam, bedah, anak, kebidanan, syaraf, gigi, THT, mata, kulit dan kelamin, kesehatan jiwa dan radiologi. yang memiliki 21 orang tenaga kefarmasian yang terdiri dari 7 orang Apoteker. Rumah Sakit Yogyakarta sebagai salah satu unsur organisasi perangkat daerah, mempunyai tugas melaksanakan upaya kesehatan yang berdaya guna dan berhasil guna dengan mengutamakan upaya penyembuhan dan pemulihan secara serasi terpadu dengan upaya peningkatan dan pencegahan serta upaya rujukan (Anonim, 2007).

Instalasi farmasi sebagai unit bisnis satu-satunya penyedia pelayanan farmasi di Rumah Sakit Kota Yogyakarta, dituntut untuk mampu memilih strategi yang tepat agar dapat meningkatkan mutu pelayanan kefarmasian yang dapat menunjang pelayanan kesehatan di rumah sakit. Berdasarkan keputusan direktur Rumah Sakit Umum Daerah Kota Yogyakarta Nomor.445/1.C/ KPTSI/2008 tentang falsafah, tujuan, visi, misi dan program kerja intalasi farmasi Rumah Sakit Kota Yogyakarta, salah satu program kerja instalasi farmasi adalah pengembangan pelayanan farmasi klinis dengan pelayanan informasi obat pasien rawat jalan (Anonim,2008).
Tujuan dari penelitian ini adalah untuk mengetahui realisasi implementasi pelayanan informasi obat pasien rawat jalan di instalasi farmasi Rumah Sakit Yogyakarta jika dibandingkan dengan target yang diinginkan.

\section{METODE PENELITIAN}

\section{A. Rancangan Penelitian}

Penelitian ini merupakan penelitian deskriptif dengan melihat dokumentasi tentang program kerja instalasi farmasi sebagai data sekunder. Wawancara serta pengamatan langsung untuk mengumpulkan data informasi obat yang diberikan kepada pasien rawat jalan di instalasi farmasi rumah sakit, sebagai bahan untuk mengevaluasi implementasi pelayanan informasi obat pasien rawat jalan instalasi farmasi Rumah Sakit Yogyakarta.

Berdasarkan data sekunder tentang program kerja instalasi farmasi Rumah Sakit Yogyakarta, sebagai salah satu program kerja instalasi farmasi adalah pengembangan pelayanan farmasi klinis dengan kegiatan pelayanan informasi obat pasien rawat jalan. Dari program kegiatan pelayanan informasi obat pasien rawat jalan, target yang ingin dicapai adalah $100 \%$ pasien rawat jalan mendapatkan pelayanan informasi obat. Data primer diperoleh melalui wawancara dengan apoteker yang bertugas melayani pasien rawat jalan dan observasi langsung. Observasi langsung dengan alat penelitian berupa lembar kerja yang berisi komponen informasi obat yang telah direncanakan untuk disampaikan oleh apoteker pada 
saat penyerahan obat kepada pasien rawat jalan.

Penentuan jumlah sampel dalam penelitian ini berdasar pendapat Roscoe bahwa jumlah sampel lebih besar dari 30 dan kurang dari 500 orang pada kebanyakan penelitian sudah terwakili (Sekaran, 2003). Berdasarkan jumlah rata-rata pasien rawat jalan instalasi farmasi sekitar 100 pasien setiap hari, maka dalam penelitian pengamatan pelayanan informasi obat pasien rawat jalan di instalasi farmasi ini, sampel yang diamati pada saat pasien menerima obat sebanyak 300 pasien. Data diambil pada bulan Januari tahun 2010 selama 6 hari pada jam 9.30 sampai jam 12.30 dengan pengamatan secara langsung komponen informasi obat yang disampaikan apoteker yang bertugas menyerahkan obat kepada pasien rawat jalan, selain menghitung persentase pasien yang menerima informasi obat juga persentase komponen informasi obat yang disampaikan kepada pasien.

\section{B. Analisis Data}

Analisis kesenjangan digunakan untuk melihat kesenjangan antara target dan realisasi dari suatu rencana atau program (Sharplin, 1985). Data dianalisis menggunakan analisis kesenjangan, untuk melihat gambaran perbedaan atau kesenjangan antara target dan realisasi implementasi pelayanan informasi obat pasien rawat jalan di instalasi farmasi Rumah Sakit Yogyakarta.

\section{Kerangka Konseptual}

Berdasarkan rancangan penelitian dan analisis data di atas, maka dibuat kerangka konsep penelitian sebagai berikut:

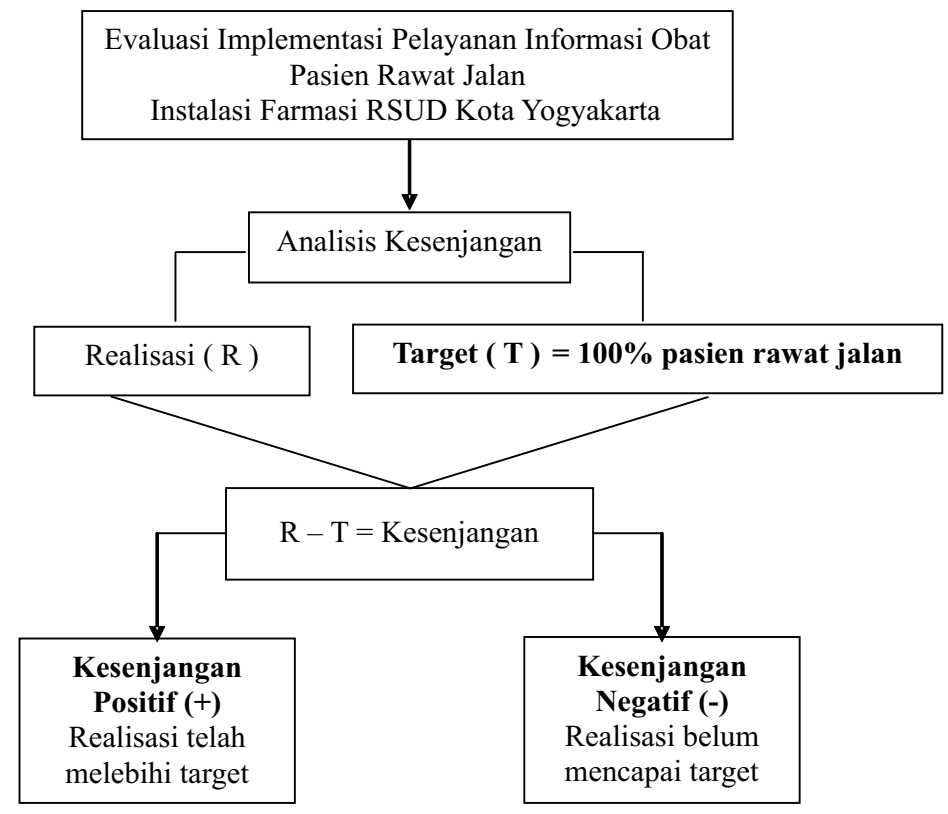

Gambar 1. Kerangka Konsep Penelitian 


\section{HASIL DAN PEMBAHASAN}

Hasil penelitian diperoleh 2 dari 300 pasien rawat jalan yang tidak diberikan pelayanan informasi obat, dengan demikian pelayanan informasi obat pasien rawat jalan sudah dapat dilaksanakan dengan realisasi sebesar $99,33 \%$ dari target yang diinginkan sebesar $100 \%$. Hasil pengamatan implementasi pelayanan informasi obat pasien rawat jalan, kemudian dianalisis dengan analisis kesenjangan dengan rumus sebagai berikut :

$$
\mathrm{R}-\mathrm{T}=\text { Kesenjangan }
$$

Pada penelitian ini, implementasi pelayanan informasi obat pada pasien rawat jalan instalasi farmasi Rumah Sakit Yogyakarta terjadi kesenjangan negatif sebesar $(-0,67 \%)$. Meskipun pelayanan informasi obat di instalasi farmasi Rumah Sakit Yogyakarta sudah terlaksana namun komponen informasi yang disampaikan kepada pasien kurang lengkap atau tidak semua komponen informasi obat yang telah direncanakan terealisasi.

Komponen informasi obat yang disampaikan oleh apoteker pada saat menyerahkan obat kepada pasien rawat jalan dapat dilihat pada Tabel 1

Tabel 1. Persentase Komponen Informasi Obat di Instalasi Farmasi Rumah Sakit Kota Yogyakarta

\begin{tabular}{|l|c|}
\hline \multicolumn{1}{|c|}{ Keterangan } & Persentase (\%) \\
\hline Khasiat & 84,33 \\
\hline Cara penggunaan & 99,33 \\
\hline Aturan pakai & 99,33 \\
\hline Lama penggunaan obat & 60,33 \\
\hline Efek samping obat & 18,00 \\
\hline Cara penyimpanan obat & 16,67 \\
\hline
\end{tabular}

Dimana

$$
\begin{aligned}
& \mathrm{R}=\text { Realisasi } \\
& \mathrm{T}=\text { Target }
\end{aligned}
$$

Dengan demikian,

Kesenjangan $=$ Realisasi - Target

$$
\begin{aligned}
& =(99,33 \%)-(100 \%) \\
& =-0,67 \%
\end{aligned}
$$

Pada Tabel 1 dapat kita amati persentase komponen informasi obat yang disampaikan pasien rawat jalan. Pelayanan informasi obat di instalasi farmasi rumah sakit kota Yogyakarta sudah terlaksana meskipun realisasinya belum dapat mencapai seperti yang ditargetkan. Pelayanan informasi obat yang meliputi khasiat, cara penggunaan, dan aturan pakai sudah terlaksana 
dengan realisasi lebih dari $80 \%$. Informasi cara penggunaan dan aturan pakai telah terealisasi sebesar $99,33 \%$, seperti yang peneliti amati secara langsung, pada saat menyerahkan obat apoteker yang bertugas selalu menginformasikan cara penggunaan dan aturan pakai obat. Sedangkan untuk informasi khasiat obat realisasi sebesar $84,33 \%$, ada beberapa obat yang tidak diinformasikan dengan alasan pasien sudah biasa menggunakan obat tersebut, terutama pada pasien yang mendapat obat yang sama dengan resep sebelumnya. Pada informasi lama penggunaan obat realisasi sebesar $60,33 \%$, informasi lama penggunaan disampaikan untuk pasien yang mendapatkan obat golongan antibiotik dan obat-obat untuk penyakit kronis seperti antidiabetes dan antihipertensi. Pemberian informasi efek samping penggunaan obat sudah terlaksana dengan realisasi sebesar $18,00 \%$, dimana realisasinya masih jauh dari target yang diinginkan. Berdasarkan pengamatan langsung informasi efek samping obat hanya disampaikan untuk beberapa pasien anak-anak dan ketika ada pertanyaan dari pasien. Untuk informasi cara penyimpanan obat terealisasi sebesar $16,67 \%$, berdasarkan pengamatan langsung cara penyimpanan obat hanya disampaikan untuk pasien yang mendapatkan obat dengan persyaratan penyimpanan khusus seperti sediaan suppositoria.

Hasil evaluasi dari realisasi implementasi program pelayanan informasi obat pasien rawat jalan, masih terjadi kesenjangan negatif atau realiasasi belum dapat mencapai target yang diinginkan. Berdasarkan analisa kesenjangan tersebut apoteker yang bertanggungjawab pada pelayanan informasi obat pasien rawat jalan ada beberapa masalah dalam implementasi program pengembangan pelayanan informasi obat pasien rawat jalan yaitu:

1. Pada pelayanan informasi obat rawat jalan, petugas kurang lengkap dalam memberikan komponen informasi obat kepada pasien.

2. Pelayanan informasi obat pasien rawat jalan di instalasi farmasi Rumah Sakit Kota Yogyakarta belum ada perkembangan untuk disampaikan dengan metode lain selain secara lisan pada saat penyerahan obat kepada pasien.

\section{KESIMPULAN}

Berdasarkan hasil analisis data tentang evaluasi implementasi pelayanan informasi obat pasien rawat jalan instalasi farmasi Rumah Sakit Kota Yogyakarta didapatkan kesimpulan, bahwa pelayanan informasi obat pasien rawat jalan terlaksana dengan realisasi sebesar $99,33 \%$ dari target $100 \%$ pasien rawat jalan mendapatkan pelayanan informasi obat. Dengan demikian terjadi kesenjangan negatif sebesar $-0,67 \%$. Komponen informasi yang disampaikan meliputi khasiat, cara penggunaan, aturan pakai, lama penggunaan obat, efek samping obat, sedangkan komponen informasi yang tidak disampaikan di instalasi farmasi Rumah Sakit Kota Yogyakarta yaitu informasi jadwal pengobatan, dan tanda-tanda toksisitas. 


\section{DAFTAR PUSTAKA}

Anonim, 2004, Standar Pelayanan Farmasi di Rumah Sakit, Direktorat Jemderal Pelayanan Kefarmasian dan Alat Kesehatan, Departemen Kesehatan Republik Indonesia, Jakarta

Anonim, 2007, Profil RSUD Kota Yogyakarta, Hal.6-8,13-15, Rumah Sakit Umum Daerah Kota Yogyakarta, Yogyakarta.

Anonim, 2008, Evaluasi Kinerja Instansi RSUD Kota Yogyakarta Tahun 2007, Hal.11-15, Rumah Sakit Umum Daerah Kota Yogyakarta, Yogyakarta.

Hunger, J.D., dan Wheelen, T.L., 2006, Strategic Management and
Business Policy, 3, 11, 16-17, 263, 10 th Edition, Prentice Hall, New Jersey.

Juliantini, E., dan Widayanti, S., 1996, Pelayanan Informasi Obat Rumah Sakit Umum Daerah Dr Soetomo, Prosiding Kongres Ilmiah XI ISFI, 3-6 juli 1996, Jawa Tengah

Sekaran, U., 2003, Research Method for Business : A Skill-Buliding Approach, $4^{\text {th }}$ Edition, John Willey and Sons, New York.

Sharplin, A, 1985, Strategik Management, Srtategy Implementation, 162, 169, Mc. Graw Hill Inc, North California. 